\title{
The School of Kiev in Colombia; the legacy of Alexander Zavadskij
}

\section{Agustín Moreno Cañadas}

Department of Mathematics, National University of Colombia

E-mail address: amorenoca@unal.edu.co

\begin{abstract}
In this paper, we give a brief biography of Alexander Georgievich Zavadskij describing his work in the field of the theory of representations of algebras and the impact of such work in the investigation of the theory of representation in Colombia. In particular, we describe the role of professor Zavadskij in the introduction of the theory of matrix problems and the poset representation theory in this country.
\end{abstract}

\section{Introduction}

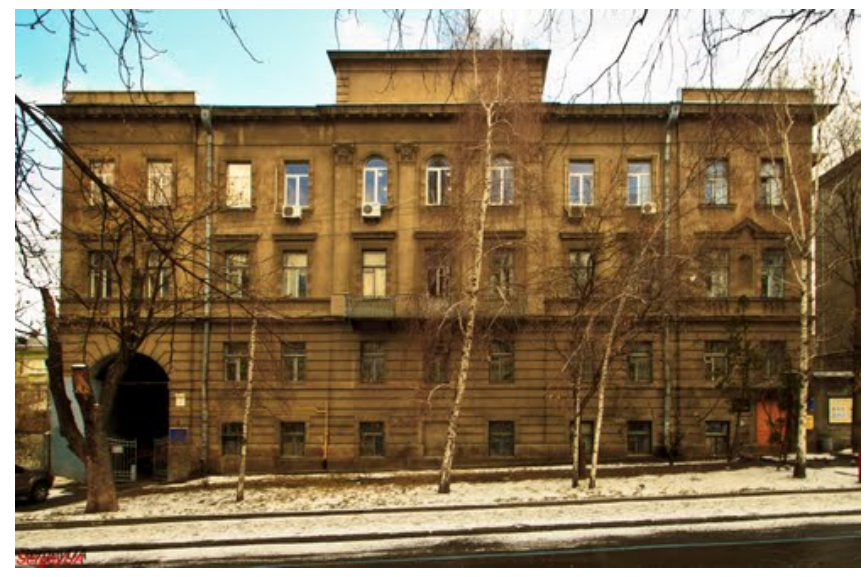

Figure 1. The Institute of Mathematics of the National Academy of Sciences, Kiev, Ukraine

2010 Mathematics Subject Classification. 16G20; 16G60; 16G30.

Key words: Alexander Zavadskij, category, equipped poset, matrix problem, morphism, $\mathcal{P}$-space, poset, representations of posets. 
The school of Kiev was originated in the algebra seminar directed by L.A. Nazarova and A.V. Roiter in the Institute of Mathematics of the National Academy of Sciences of Ukraine. One of the main theoretical concepts developed by the school of Kiev was the theory of matrix problems and, in particular, the theory of representations of posets $[17,18,28]$. According to Simson [28] the representation poset theory is the first well-developed part of the theory of vector space categories introduced by Nazarova and Roiter and successfully applied in their proof of the second Brauer-Thrall conjecture $[21,22]$. We recall that, Bautista and then Bongartz proved the second conjecture of Brauer-Thrall based in a result obtained jointly with Roiter, Gabriel and Salmeron $[2,6,28]$.

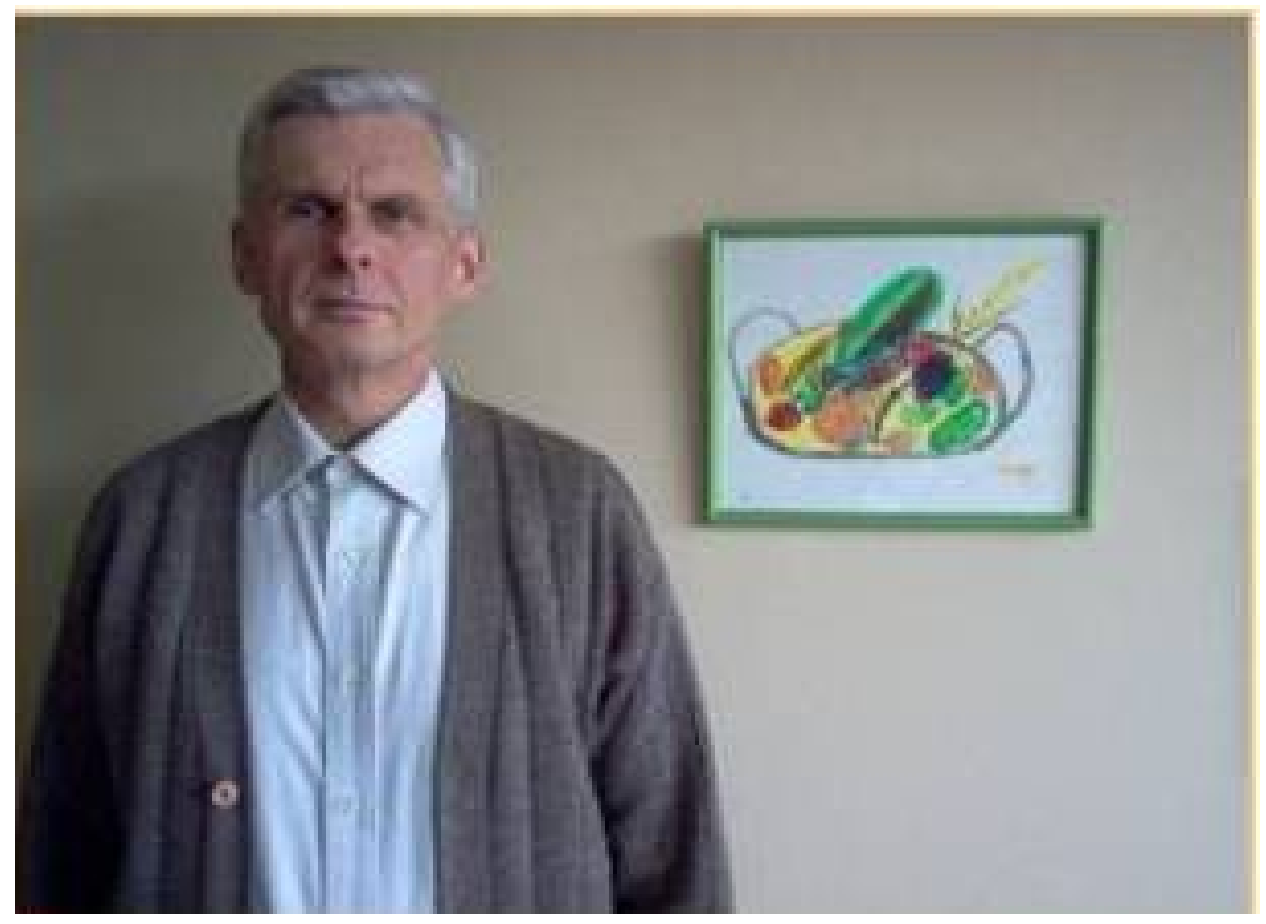

Figure 2. Alexander Zavadskij in Bogotá, Colombia.

A.G. Zavadskij was a member of the school of Kiev. The works published by Zavadskij in collaboration with some of its members are remarkable [5, $15,22,23,29,32,33$. Perhaps the most important result given by Zavadskij was the algorithm of differentiation with respect to a suitable pair of points 
(see Figures 17 and 18) which in particular allowed him and Nazarova to obtain a criterion for posets of finite growth representation type [23].

In this paper, we describe the most important results obtained by Zavadskij and the impact of his work on the development of the representation theory in Colombia.

\section{Early life and career}

Alexander Georgievich Zavadskij was born in Kiev-Ukraine 5 August 1946. His parents were Nadezhda Moiseevna Kolovskaya and Georgij Petrovich Zavadskij a colonel of the ancient Soviet Union. Alexander knew his wife Ludmila at the university and they had two sons, Igor and Aleksej and two grandchildren Darina and Bogdan who survive him.
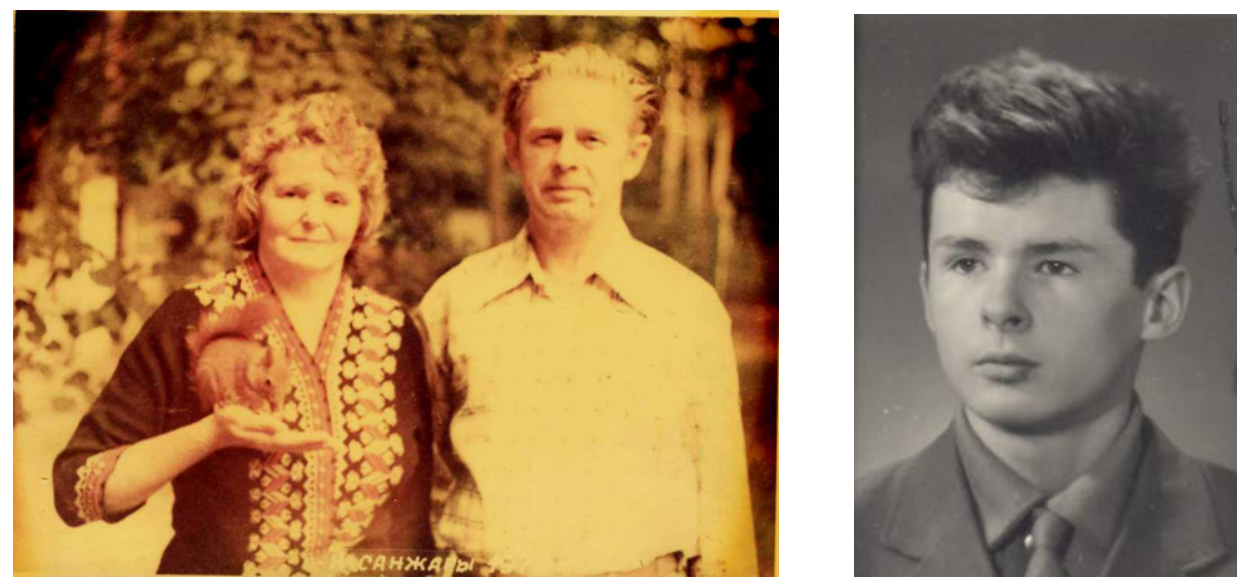

FIGURE 3. Zavadskij's parents and a young Zavadskij.

Zavadskij was really a gentleman of the science. He was a brilliant student at the Department of Mechanics and Mathematics of Kiev State University named after T.G. Shevchenko in Ukraine and obtained his first degree in Mathematics in 1968 with a work entitled p-Complete Abelian Groups supervised by professor Lev Arkadievich Kalujnin. Often, professors were taking into account comments and corrections given by him to solutions of different problems. Later, as a professor, Zavadskij was appreciated by his students and colleagues for his good humor, compromise, honesty and principles. 


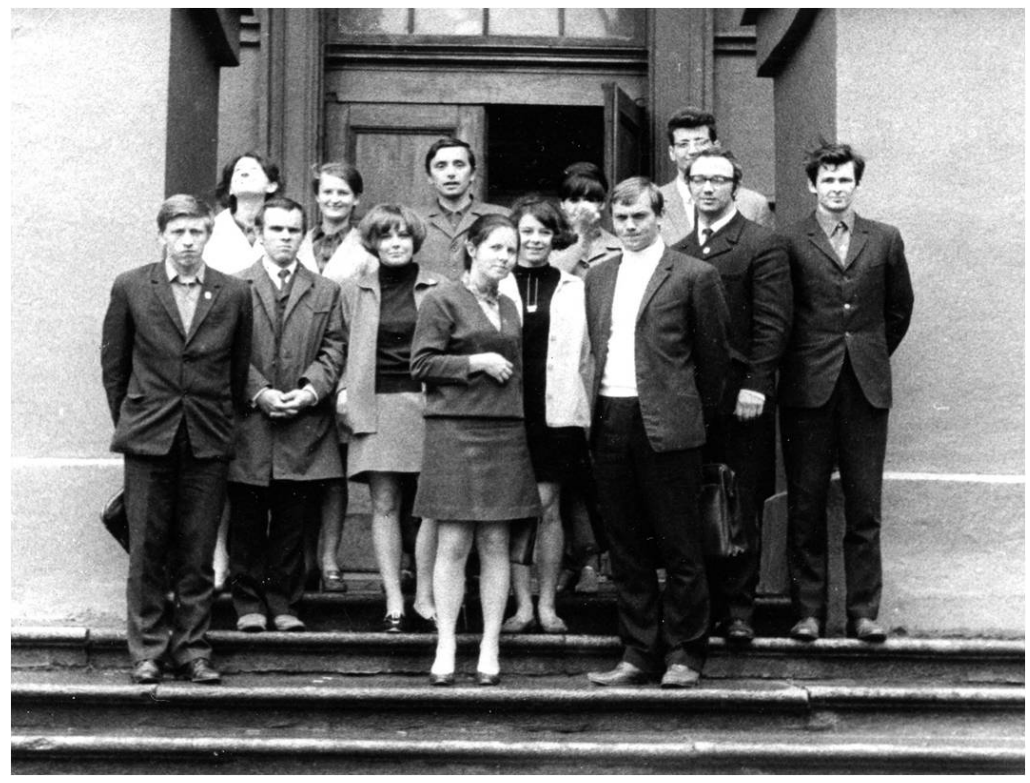

FIgURE 4. Zavadskij his future wife (second woman in the second row from the left to the right) and some of their colleagues in KSU, 1970.

In 1970 he completed his specialist's degree in KSU, the title of his work was Almost Bass Orders Completely Decomposable supervised by professor Vladimir Vasilyevich Kirichenko. We recall that, Zavadskij was the first student of Kirichenko.
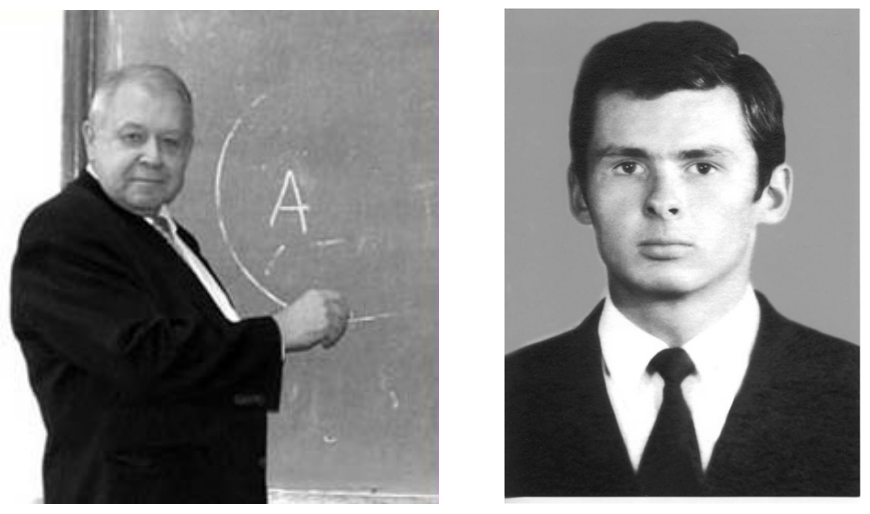

FiguRE 5. V.V. Kirichenko and his first student A.G. Zavadskij. 
In the next three years, Zavadskij was a research engineer of the Kiev Institute of Automation. In this period, he wrote his doctoral dissertation, this due that, he was not admitted in the first instance as doctoral student in KSU, because he failed the history examination of the Communist Party of the Soviet Union.

\section{Research}

Zavadskij realized his investigation in two main periods: the first stage of his investigation between 1970 and 2001 was developed in Kiev-Ukraine, with a short stay in Mexico between 1994 and 1996, whereas the second stage of Zavadskij's research was realized in Bogotá-Colombia between 2001 and 2011.

3.1. Ukraine. Zavadskij completed his doctoral studies in KSU in 1974 with a dissertation entitled The Structure of all Orders whose Representations are Totally Decomposable again supervised by professor Vladimir Vasilyevich Kirichenko. In 1992, Zavadskij received his degree of Doctor of Sciences with a dissertation entitled Representations of Partially Ordered Sets of Finite Growth. Official opponents for his defence were P.M. Gudivok and A.V.Roiter.

We note that, only eight members of the Kiev school received a Doctor of Science degree and one of them was professor Zavadskij [6].

He worked as a professor in the Kiev National University of Construction and Architecture (KNUCA) between 1972 and 2001. As an Assistant Professor in the period 1972-1973, as an Associate Professor between 1972-1991 and finally, as a Full Professor in the period 1992-2001.

As we have written above, Zavadskij obtained his doctoral degree in 1974. Soon afterwards, he discovered the algorithm of differentiation with respect to a suitable pair of points, called by him DI. This algorithm has had a high-impact on the theory of representations and it may be the major contribution of Zavadskij to this theory. In order to support this claim, we must say that DI generalizes the algorithm with respect to a maximal point previously defined by Nazarova and Roiter. Actually, until now, the main tools to classify posets have been the algorithms of differentiation. Such algorithms are functors giving a relationship between the category of representations of a given poset $\mathcal{P}$ and the category of representations of a corresponding derived poset $\mathcal{P}^{\prime}$. In fact, the main criteria to classify ordinary posets of finite, tame and finite growth type were found by Kleiner in 1972, Nazarova in 1975, and Nazarova and Zavadskij in 1981 respectively, 


\section{WHHYCTEPCTBO BUCWETO И CPEMHETO \\ СПЕЧИАЛЬНОГО ОВРАЗОВАНИЯ УССР}

Киевский ордена Трудового Красного Знамени инденерно-строительни институт

На правах рукописи

удाК $5 I 2.6$

ЗАВАДСКи Александр Георгиевич

IIРЕДСТАВЛЕНИЯ ЧАСТИЧНО УПОРЯДОЧЕННЫХ МНОЖЕСТВ КОНЕЧНОГО РОСТА

OI.OI.06 - матецатическая логика, алгебра и теория чисел

д и С С В $\mathrm{P}$ Т А म и я

на соискание учено степени доктора физико-математических наук

Кнев - I988

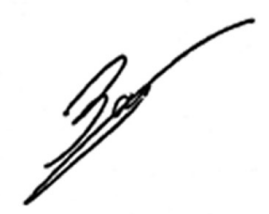

FiguRE 6. Original title of Zavadskij's thesis. 
with the help of the algorithm of differentiation with respect to a maximal point and algorithm DI [19,21-23,40].

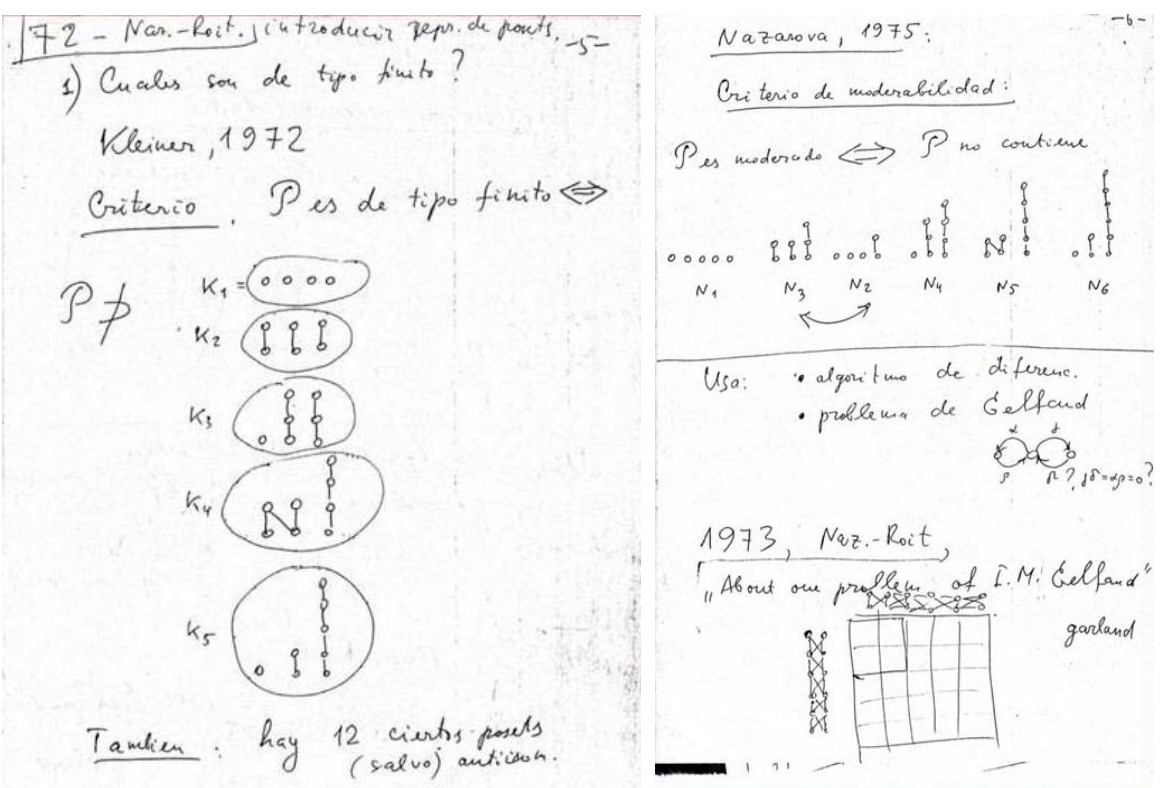

FiguRE 7. Finite and tame representation type criteria written by Zavadskij in Spanish for his students in Colombia.

We must note that according to Simson [28] the main idea used by Nazarova and Roiter in their solution of the second Brauer-Thrall conjecture is to reduce it to a corresponding one for some categorical matrix problems and consequently to representations of finite partially ordered sets.

Methods of poset representation theory were also successfully applied to classify different type of rings. For instance, critical posets obtained by Kleiner were used by Zavadskij and Kirichenko in order to give a criterion for tiled orders of finite representation type [28,32]. Kleiner's well known finite type criterion was also used by Zavadskij and his doctoral student in Kiev U. Revitskaya in order to obtain a criterion for module boundedness, such criterion is stated in terms of a pair of partially ordered sets $(\mathcal{P}(A), \mathcal{P}(B))$ associated with a pair of transforming algebras $(A, B)$ defining the problem [24]. Finally, we would like to point that Arnold described some relationships between Butler groups and representations of 


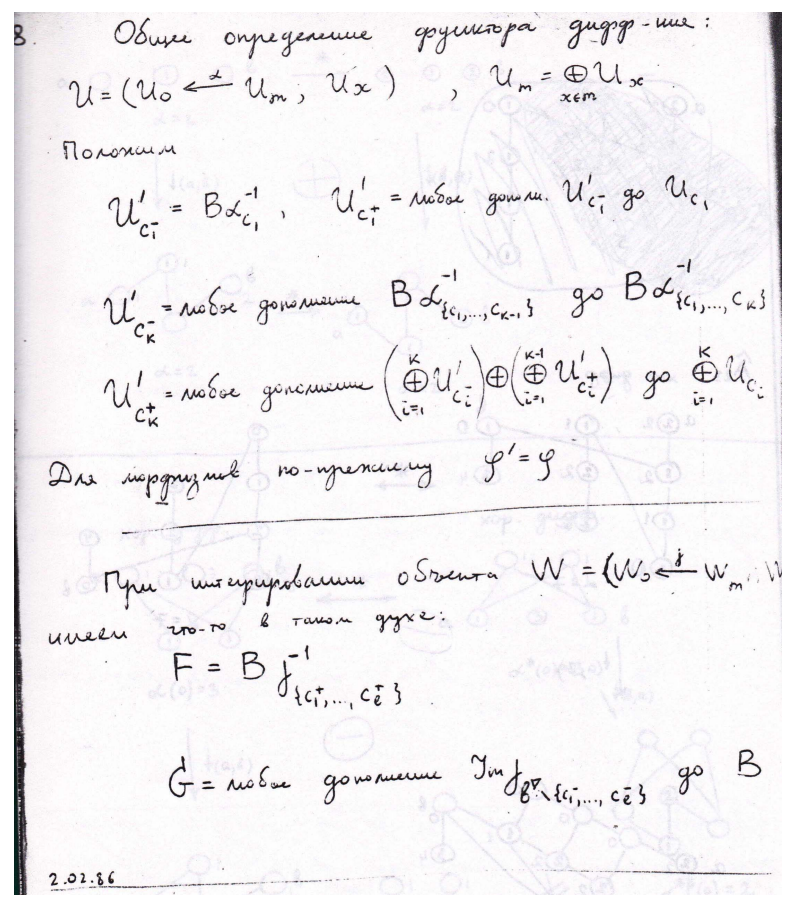

Figure 8. Zavadskij described the Gabriel version of DI in his 2-02-1986 diary entry.

finite posets over discrete valuation rings. According to Arnold [1] computations of representation type of representations of posets over discrete valuation rings lead to explicit procedures for constructing indecomposable almost completely decomposable groups of arbitrarily large finite rank with types in a fixed finite set of types. Such constructions are quite difficult without the assistance of techniques from representation theory.

At the end of the 1980s one of the most important topics in the study of the representation of posets was the classification of posets with additional structures. For example, in 1991, Bondarenko, Nazarova and Roiter obtained a criterion for posets with involution of tame representation type in the case when distinct involutory elements are always noncomparable, and Bondarenko and Zavadskij obtained criterions of tame and finite growth representation type for posets with an equivalence relation (which include the general case of posets with involution) [3-5]. In particular, at the end of the 1990s, Zavadskij and his other doctoral student in Kiev A. Zabarilo (see Figure 19) introduced the concept of equipped posets, they also 
described the one-parameter equipped posets and gave a complete classification of their indecomposable representations. According to Zavadskij the correlation between representations of equipped posets with ordinary posets is analogous to the correlation of representations of valued graphs with representations of ordinary graphs $[11-13,30]$.

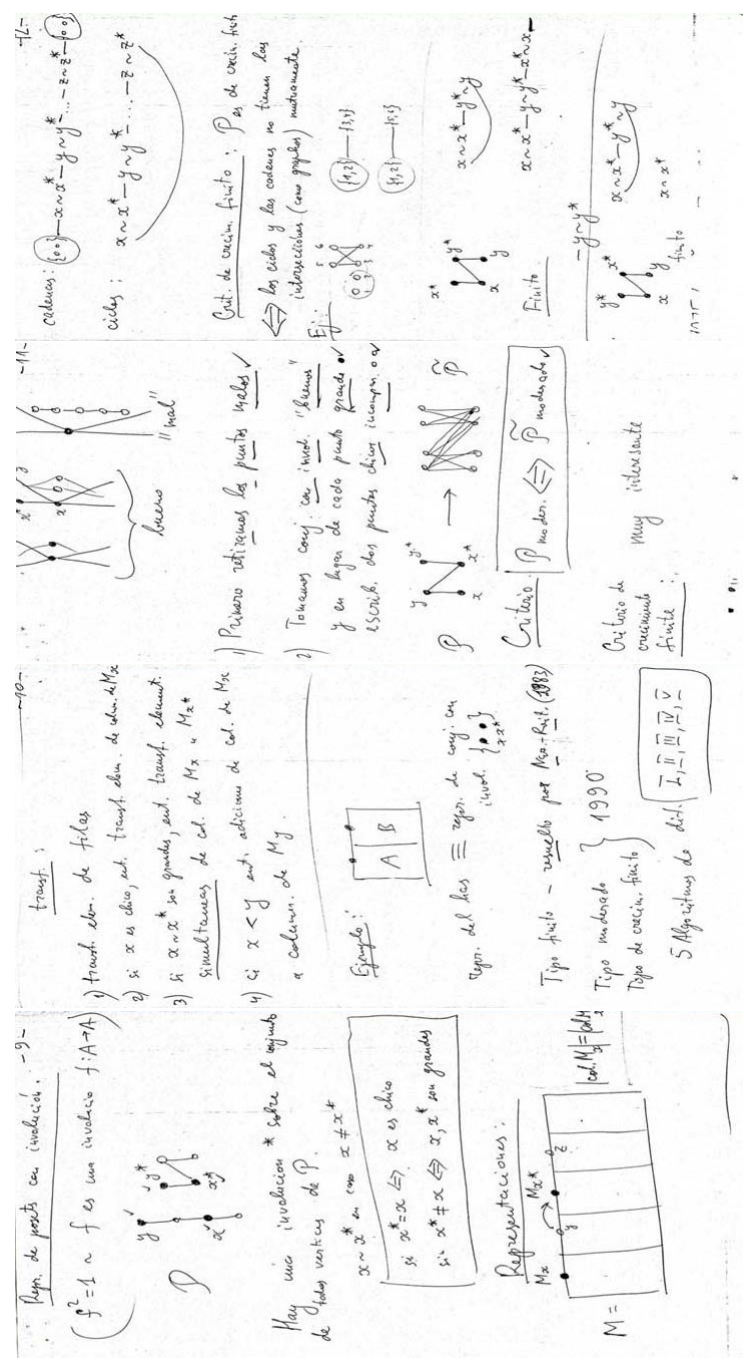

Figure 9. Posets with involution (with an equivalence relation) and criteria of finite growth and tame representation type written by Zavadskij for his students in Colombia, 2002. 

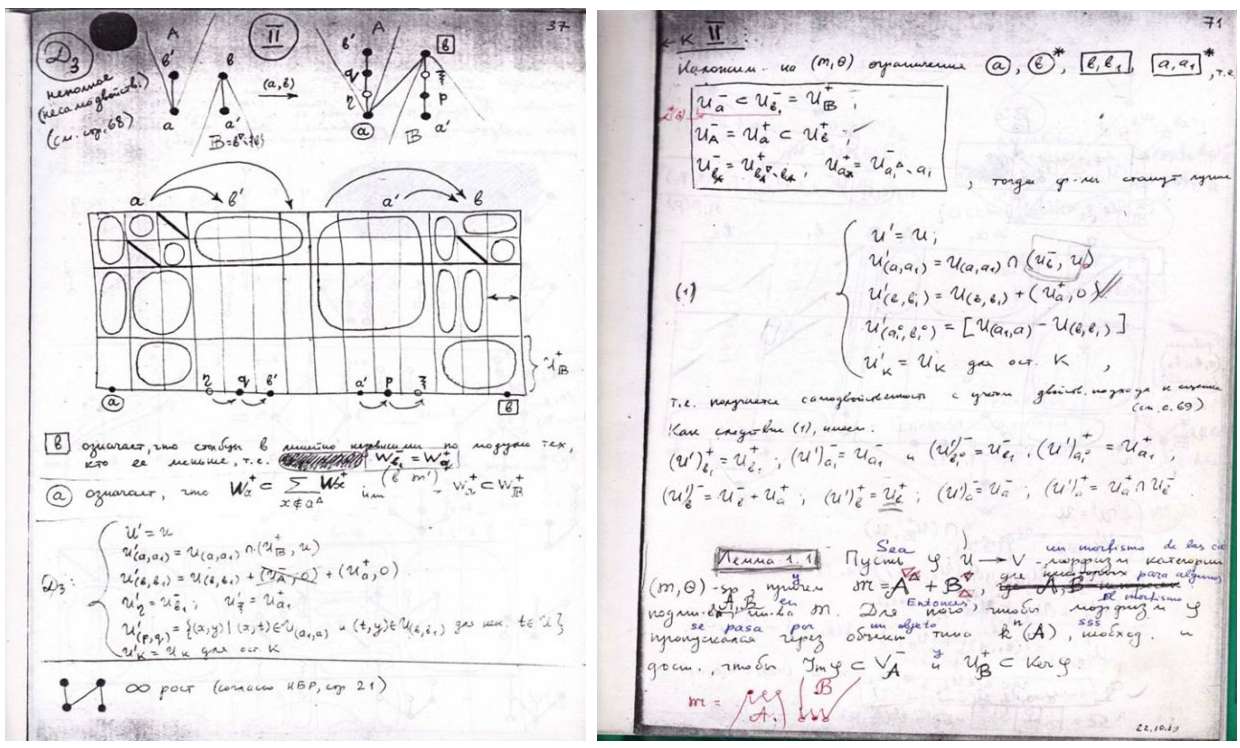

FiguRE 10. Entries of Zavadskij's diary (one of them dated 22-10-1989) where he described the algorithm DII and a corresponding Gabriel version of this algorithm. In these notes, Zavadskij also wrote the fundamental theorem for morphisms between the corresponding categories of representations for posets with involution and a pair of points II-suitable.

Soon afterwards, Zavadskij described tame and wild equipped posets with the help of newly developed algorithms of differentiation VII-XVII for this kind of posets. In particular, algorithms VII, VIII, and IX allowed him to find out a criterion for equipped posets of finite growth. A list of sincere equipped posets of finite growth was found by Zavadskij as well $[38,39]$.

So far, the investigation of the theory of the algorithms of differentiation has been oriented to the study of how these functors transform objects of the corresponding categories, without paying much attention to the investigation of how morphisms can be transformed under the action of such functors. Actually, some of the few works dealing with this topic have been written by Gabriel, Giraldo, the author (a Zavadskij's colombian doctoral student, see Figure 19), Zavadskij, and Rump. Gabriel gave the categorical interpretation of the algorithm of differentiation with respect to a maximal point of Nazarova and Roiter in [16]. On the other hand, in [7, 9, 10,34] Cañadas and Zavadskij investigated some categorical properties of some algorithms of differentiation for posets with involution, equipped posets and 

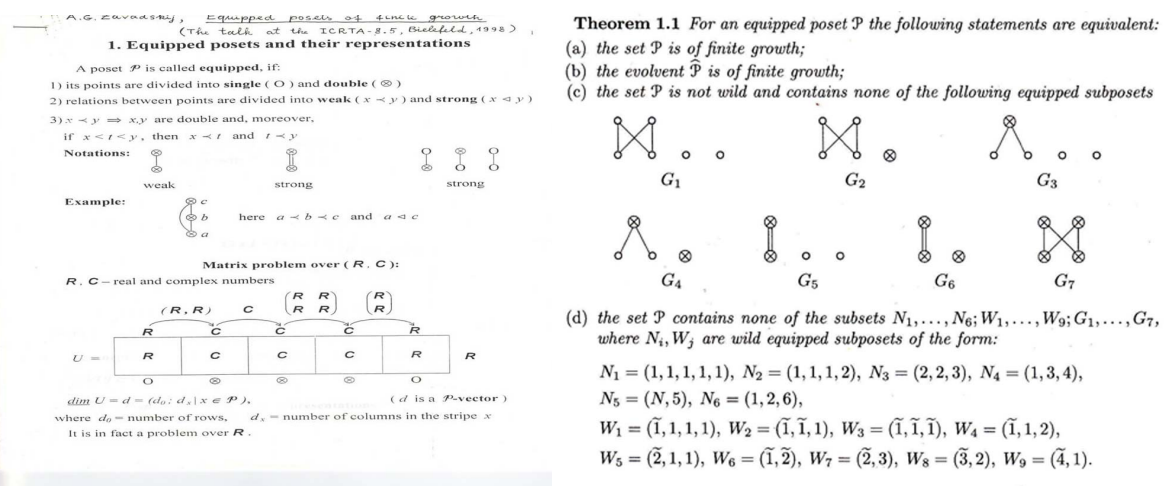

FiguRE 11. A slide of the talk given by Zavadskij in Bielefeld-1998 (ICRA) where the original idea of equipped posets is explained and Zavadskij's finite growth representation type criterion.

posets without additional structures. In particular, in [40] Zavadskij gave a generalization to posets with some lattice relations, the categorical description of the algorithm DI for ordinary posets given by him in [34]. Another generalization of this categorical description (to semiabelian categories) was given by Rump in [27].

\section{Mexico}

Zavadskij visited Mexico between 1994 and 1996. In this period he worked with professors R. Bautista and J.A. De la Peña of UNAM, two important papers were written as a consequence of this collaboration giving criteria of tame and finite growth representation type for posets both ordinaries and with additional structures with the help of six algorithms (DI-DVI) of differentiation obtained by him $[36,37]$. These results were presented at ICRA VII, Cocoyoc-Mexico, 1994 and ICRA VIII, Geiranger-Norway, 1996. We must recall that Zavadskij also visited professors D. Simson in Torun-Poland, 1985, and C.M. Ringel in Bielefeld-Germany, 1991 and 1999.

\section{Colombia}

The second stage of the Zavadskij's investigation was performed in Bogotá, Colombia between 2001 and 2011. In 2001, He won a position as professor in the Department of Mathematics of the National University of Colombia among the documentation sent by him to this university there were a recommendation letter written by professor R. Bautista and a work plan 


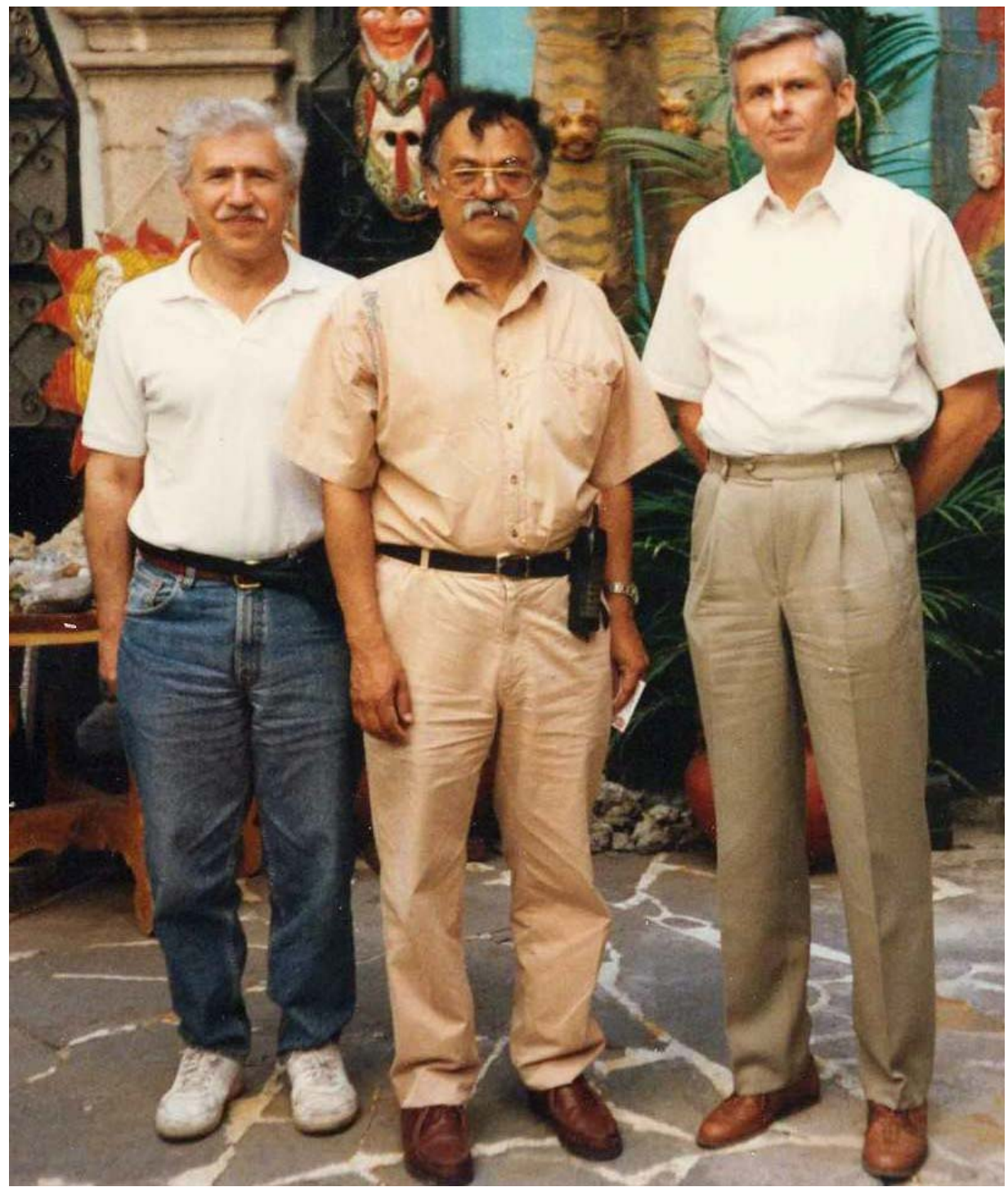

FiguRE 12. Kleiner, Bautista and Zavadskij during his 1994-1996 stay in Mexico.

describing his future research in theory of representations. The plan had five items and it was described as follows:

(1) To work out the differentiation technique for tame equipped posets. 


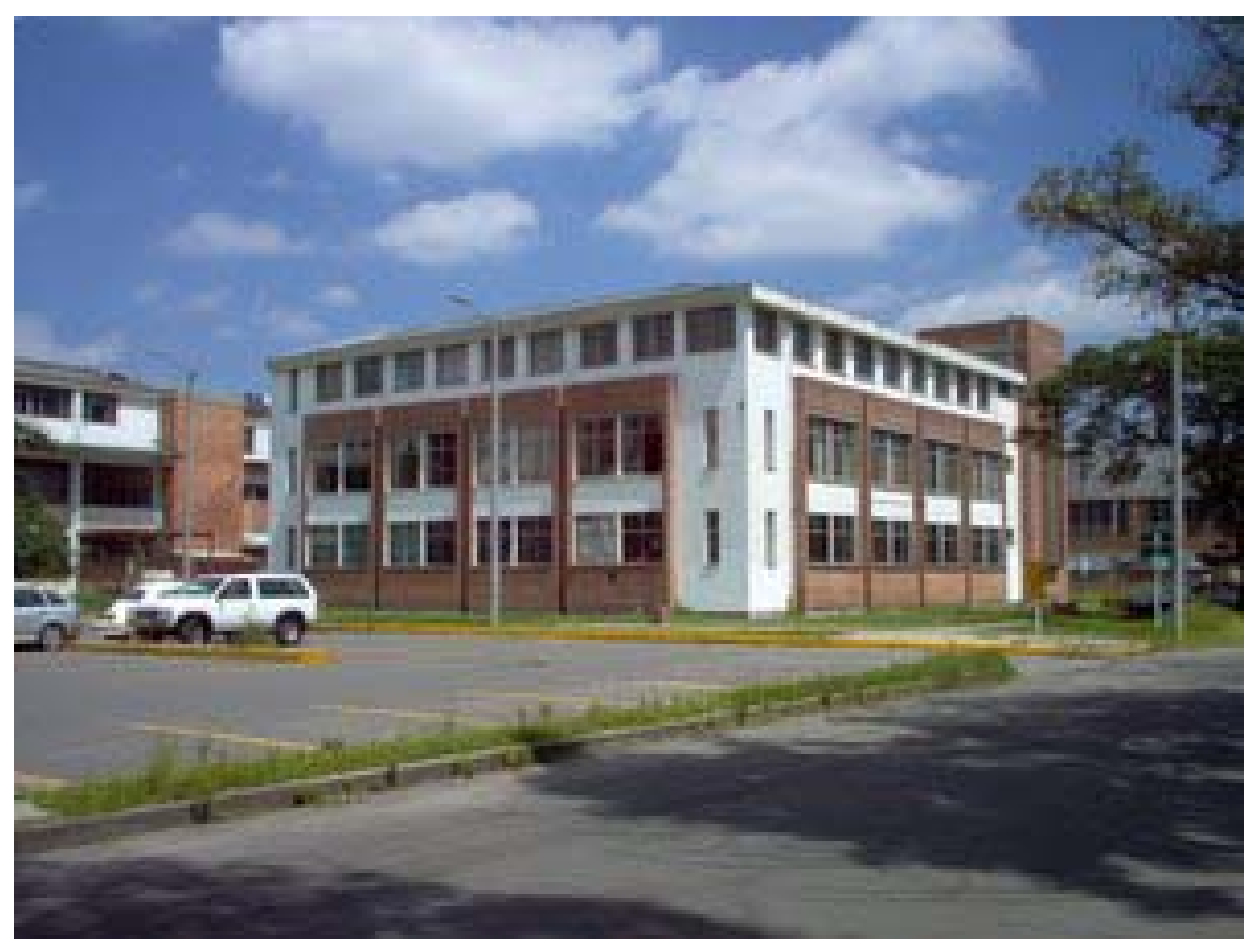

FiguRE 13. Department of Mathematics of the National University of Colombia (Bogotá)

(2) To obtain by means of the constructed algorithms criteria of tame and finite growth representation type for equipped posets.

(3) To describe the series of indecomposables equipped posets of finite growth (and to establish the connection with Tits quadratic form).

(4) To obtain the list of all sincere equipped posets of finite growth (extending the corresponding list for ordinary posets).

(5) To investigate perspectives for a future description of categories of tame representation type in the following situations:

(a) Equipped posets with involution

(b) Graphic (or more general) vectroids

(c) Flat matrix problems of mixed type over different rings.

He was an Assistant Professor in the National University of Colombia between 2001 and 2002. In period 2002-2009 he was an Associate Professor and a Full Professor between 2009 and 2012. He obtained category of Full Professor with a work entitled On Some Classification Problems of Linear Algebra and Their Applications to the Representation Theory written in 
2006, in the same year, he was honored with the Award of Merit of the National University of Colombia for his high-quality research.

Zavadskij's working plan was implemented almost immediately. First of all, he organized three doctoral seminars. The first one, on the linear representations of finite groups was directed by him and professor V.S. Albis (a professor of the Department of Mathematics). The second and the third ones were on representations of finite-dimensional algebras and on representations of partially ordered sets. At this point, we must recall that the theory of matrix problems was not known in Colombia before the arrival of Zavadskij to Colombia, so that in order to give a major motivation to his students, Zavadskij always began his lectures concerning the poset representation theory with some interesting historical remarks describing advances in the research on the topic.

The third seminar, concerning representations of posets motivated Zavadskij to create an interesting course called Topics on Partially Ordered Sets. In this course he discussed with students advances in the poset representation theory, in particular, the results obtained by him concerning posets with additional structures (see Figure 14).

5.1. Papers and talks. Papers [38,39], giving criteria of tame and finite growth representation type for equipped posets, were written by Zavadskij between 2001 and 2003. In [38] Zavadskij defined algorithms VII-XVII for equipped posets, these algorithms allow him to obtain such criteria. In 2003, Zavadskij wrote [40] where his algorithm DI with respect to a suitable pair of points was generalized to posets with some lattice relations. Soon afterwards, Zavadskij published [41] and [42] where he considered some matrix problems over a quadratic skew field extension and some classification problems of linear algebra related to the classical problem of Kronecker on pairs of linear maps between two finite-dimensional vector spaces, respectively. In his last published paper [43] he classified representations of generalized equipped posets over a Galois field extension. We must note that the papers $[5,24,30]$ were crucial for Zavadskij's colombian doctoral students. In particular, $[5,30,31]$ and [38] could be considered as starting points for doctoral thesis of the author, I. Dorado and C. Rodriguez (see $[9,10,14],[26]$ and Figure 19). We note that [20] was the first paper (concerning the four subspaces problem) written by Zavadskij jointly with a colombian student (G. Medina).

The first talk given by Zavadskij in a national event (XV National Congress of Mathematics-2005-Bogotá-Colombia) was entitled Differentiation Method in the Poset Representation Theory. Although this talk was given 


\section{Curso: Temas de Conjuntos Ordenados}

Código 2019116, Semestre 2011-2 (64 horas)

Profesor Oleksandr Zavadskyy (Of. 405-326, Ext. 13215)

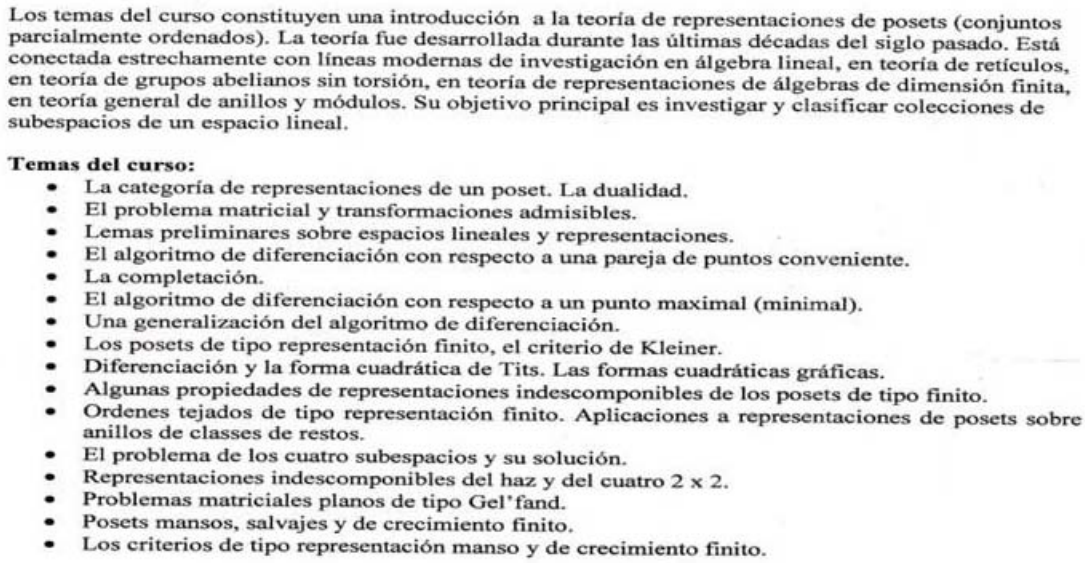

BIBLIOGRAFIA

1. D. Arnold, Abelian groups and representations of finite partially ordered sets. CMS Books in M. Gematics, Volume 2, 2000 .

. P. Gabriel, A.V. Roiter. Representations of Finite-dimentional Algebrais. Algebra VIII, Encyclopedia of Math. Sc., Vol. 73, Springer, 1992.

3. C.M. Ringel. Tame Algebras and Integral Quadratic Forms. Lecture Notes in Math., Vol. 1099, Springer, 1984

*4. D. Simson. Linear Representations of Partially Ordered Sets and Vector Space Categories. Gordon and S. Breach, London, 1992.

G. Medina, A.G. Zavadskij, The four subspace problem: an elementary solution. Linear Algebra

and its Appl., 392 (2004), 11-23. A.G. Zavadskij. On two-point differentiation and its generalization, Algebraic structures and their
representations, AMS, Contemporary Math. Ser., 376 (2005), 413-436.

Figure 14. Table of contents of the course Topics of Partially Ordered Sets written by Zavadskij in Spanish.

in English, he was not sure that it was the appropriate language for a colombian audience. Actually, he preferred giving his talks in Spanish for a better understanding of students.

Categorical Description of Some Differentiation Algorithms was the title of the first international talk (ICRA-XI-2004-Patzcuaro-Mexico) given by Zavadskij jointly with a colombian student (the author). 


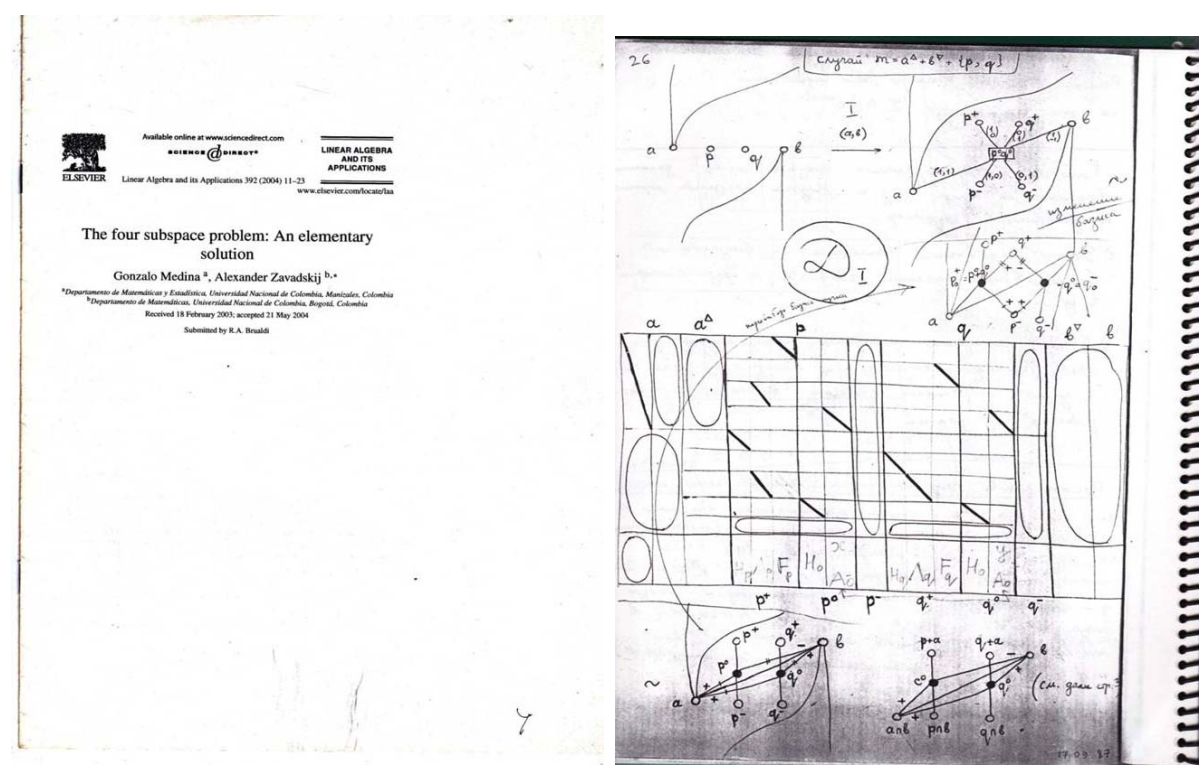

Figure 15. The first paper written by Zavadskij jointly with a Colombian student and some ideas concerning some relations between DI and the four subspaces problem written by Zavadskij in his 17-09-1987 diary entry.

The following is the modern categorical version of DI described by Zavadskij in [40]:

$$
\begin{aligned}
U_{0}^{\prime} & =U_{0} \\
U_{c_{i}^{+}}^{\prime} & =U_{a+c_{i}}=U_{a}+U_{c_{i}} \\
U_{c_{i}^{-}}^{\prime} & =U_{c_{i} b}=U_{c_{i}} \cap U_{b} \\
U_{x}^{\prime} & =U_{x} \quad \text { for the remaining points } x \in \mathcal{P}^{\prime} \\
\varphi^{\prime} & =\varphi \quad \text { for all linear map }- \text { morphism } \varphi: U_{0} \rightarrow V_{0} .
\end{aligned}
$$




\section{Universidad Nacional de Colombia Facultad de Ciencias Departamento de Matemáticas}

\section{Reportes Internos}
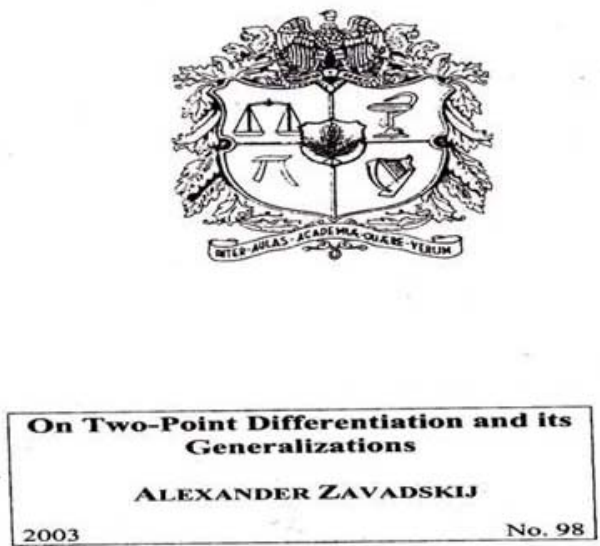

Bogotá, D. C., Colombia e-mail:uninv@matematicas.unal.edu.co htpp:.matematicas.unal.edu.co/uninv

FIGURE 16. 2003-Preprint of the Zavadskij's paper, On two point differentiation and its generalizations, where it is introduced a modern generalized version of DI.
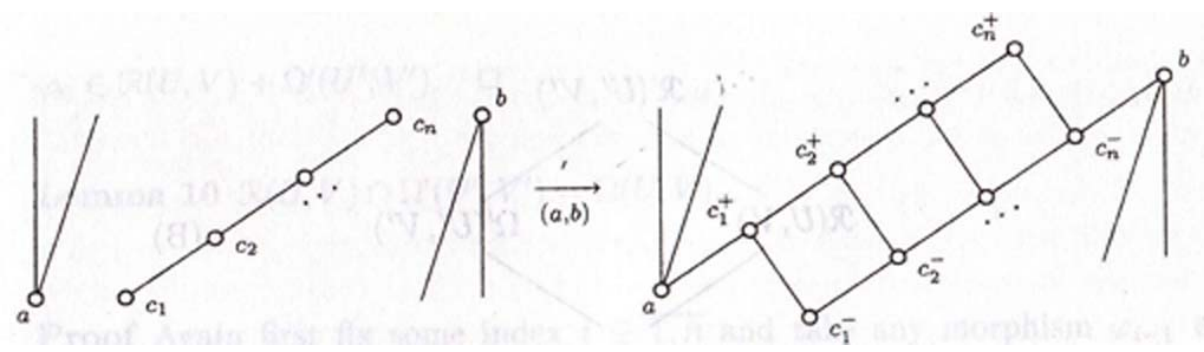

Figure 17. Hasse diagram of DI.

\section{The legacy}

The Zavadskij's legacy (see Figure 20) consists of a list of open problems in the poset representation theory. These problems were described by Zavadskij to his students in Colombia. 


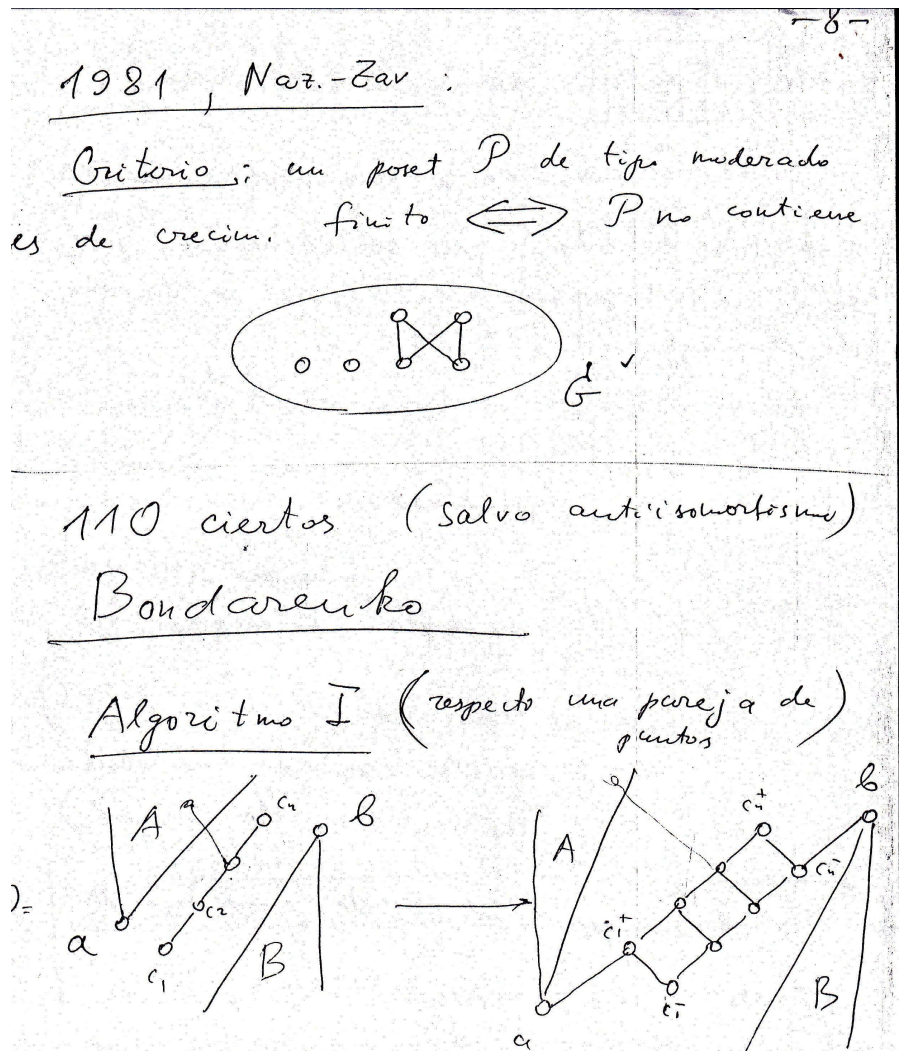

FIGURE 18. Finite growth representation type criterion and DI written in Spanish by Zavadskij for his colombian students.

The following are the most salient problems proposed by Zavadskij in his legacy:

(1) To describe all indecomposable representations of posets with involution both of tame and finite growth representation type.

(2) To give a complete categorical description of all algorithms of differentiation.

(3) To describe commutative quivers of tame representation type.

(4) To solve mixed matrix problems (over different fields) (i.e., to classify generalized equipped posets and equipped posets with involution).

Problem 1 has been investigated by Bondarenko, Nazarova, Roiter and Zavadskij in $[4,5]$ and [35]. Problem 2 has been investigated by the author, 


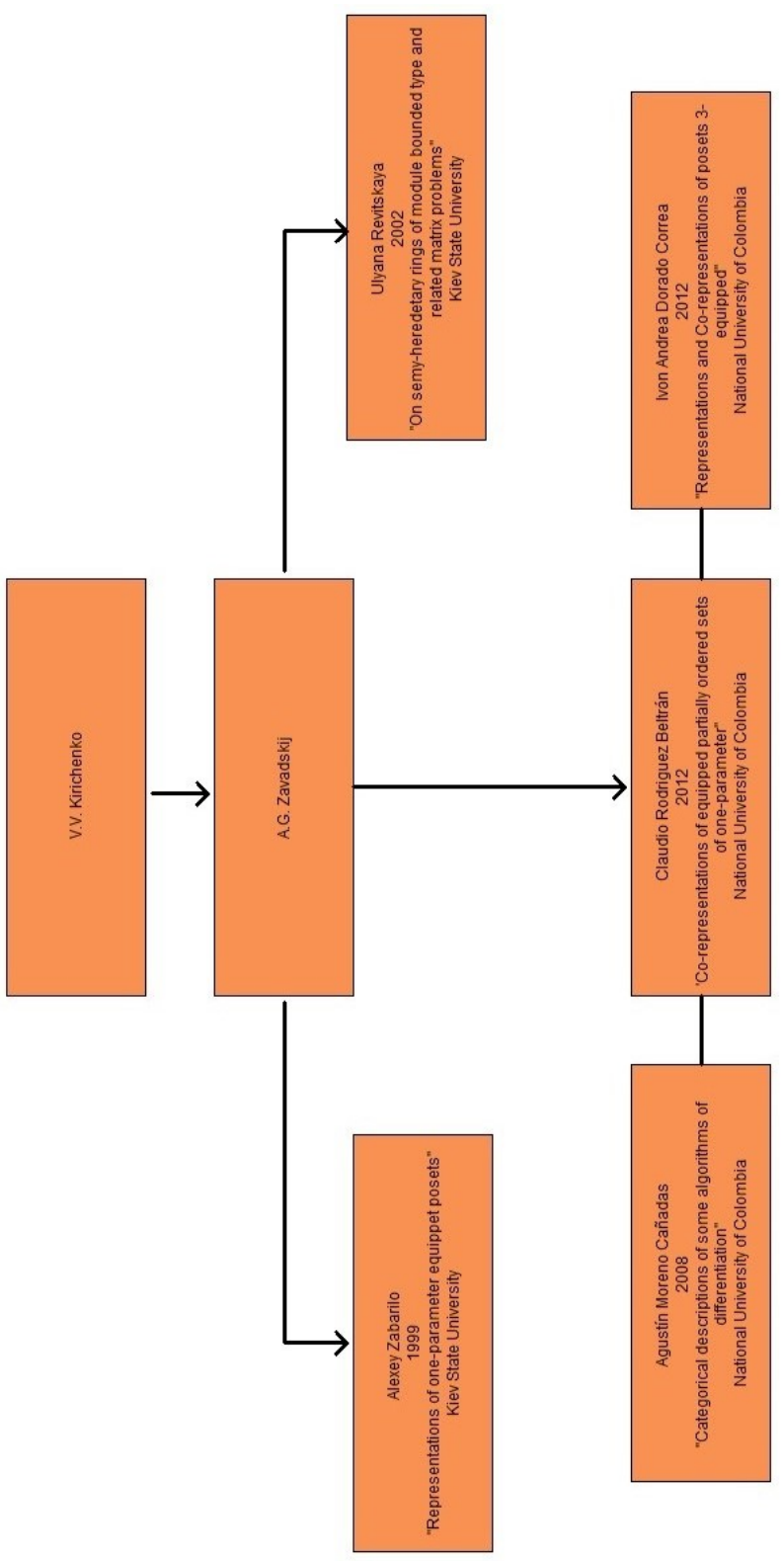

Figure 19. A list of Zavadskij's doctoral students. 

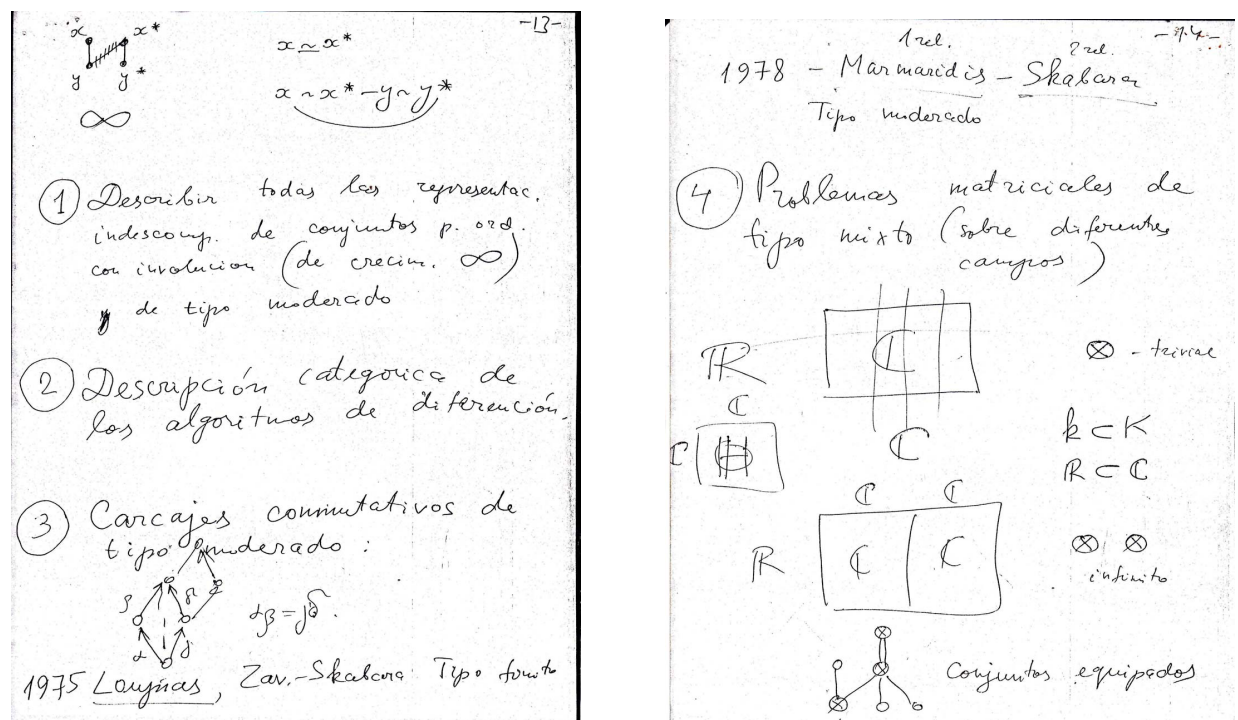

Figure 20. The Zavadskij's legacy written in Spanish by him.

Gabriel, Giraldo, Rump and Zavadskij in [7-10,16,27] and [34]. Problem 3 has been investigated by Shkabara and Zavadskij in [29]. Problem 4. has been investigated by Dorado, Rodriguez, Zabarilo and Zavadskij in $[14,25,26,30,38,39]$ and $[43]$.

Professor A.G. Zavadskij died in Bogotá-Colombia on 02 February 2012.

\section{Acknowledgements}

The author is indebted to professor A.G. Zavadskij for his patience and wise guidance during his stay in Bogotá-Colombia. We also would like to thank Mrs. Ludmila Zavadskaya for her helpful information, suggestions and comments.

\section{References}

[1] D.M. Arnold, Abelian Groups and Representations of Finite Partially Ordered Sets, CMS Books in Mathematics, vol. 2, Springer, 2000. 244 p.

[2] R. Bautista, P. Gabriel, A.V. Roiter, and L. Salmeron, Representation-finite algebras and multiplicative bases, Invent. Math. 81 (1985), 277-285.

[3] V.M. Bondarenko, L.A. Nazarova, and A.G.Zavadskij, On representations of tame partially ordered sets, Amer.Math.Soc.Trasl. (2),128 (1986), 57-78.

[4] V.M. Bondarenko, L.A. Nazarova, and A.V. Roiter, Tame partially ordered sets with involution, Proc. Steklov Inst. Math 183 (1991), 177-189. 
[5] V.M. Bondarenko and A.G. Zavadskij, Posets with an equivalence relation of tame type and of finite growth, Can. Math. Soc. conf. Proc 11 (1991), 67-88.

[6] V.M. Bondarenko, YU. A. Drozd, V.V. Kirichenko, M. Kleiner, S.A. Kruglyak, and S.A. Ovsienko, In memory of Andrei Vladimirovich Roiter (2006). www.mathematik.uni-bielefeld.de/ sek/ collect/ roiter.pdf.

[7] A.M. Cañadas and A.G. Zavadskij, Categorical description of some differentiation algorithms, Journal of Algebra and Its Applications 5 (2006), no. 5, 629-652.

[8] A.M. Cañadas, Morphisms in categories of representations of equipped posets, JPANTA 25 (2012), no. 2, 145-176.

[9] Categorical properties of the algorithm of differentiation VII for equipped posets, JPANTA 25 (2012), no. 2, 177-213.

[10] A.M. Cañadas and H. Giraldo, Completion for equipped posets, JPANTA 26 (2012), no. 2, 173-196.

[11] V. Dlab and C.M. Ringel, Indecomposable representations of graphs and algebras, Memoirs Amer. Math. Soc 173 (1973).

[12] _ Real subspaces of a quaternion vector space, Can. J. Math. 30 (1978), 12281242.

[13] V. Dlab, Representations of valued graphs, Les presses de l'université de Montreal, 1980. ISBN-2-7606-0503-5.

[14] I. Dorado, Three-equipped posets and their representations and corepresentations (inseparable case), Linear Algebra Appl. 433 (2010), 1827-1850.

[15] YU. A. Drozd, V.V. Kirichenko, and A.G. Zavadskij, Matrix problems and integer representations, Izvestiya Akad Nauk Sssr 38 (1974), no. 2, 291-293.

[16] P. Gabriel, Représentations indécomposables des ensemblés ordonnés, Semin. P. Dubreil, 26 annee 1972/73, Algebre, Expose 13 (1973), 301-304.

[17] P. Gabriel and A.V. Roiter, Representations of Finite Dimensional Algebras, Algebra VIII, Encyclopedia of Math. Sc., vol. 73, Springer-Verlag, 1992. 177p.

[18] M. Hazewinkel, N. Gubareni, and V.V. Kirichenko, Algebras, Rings and Modules, First Edition, Vol. 2, Springer, 2007.

[19] M.M. Kleiner, Partially ordered sets of finite type, Zap. Nauchn. Semin. LOMI 28 (1972), 32-41 (in Russian); English transl., J. Sov. Math 3 (1975), no. 5, 607-615.

[20] G. Medina and A.G. Zavadskij, The four subspace problem; An elementary solution, Linear Algebra Appl. 392 (2004), 11-23.

[21] L.A. Nazarova and A.V. Roiter, Representations of partially ordered sets, Zap. Nauchn. Semin. LOMI 28 (1972), 5-31 (in Russian); English transl., J. Sov. Math. 3 (1975), 585-606.

[22] L.A. Nazarova and A.G. Zavadskij, Partially ordered sets of tame type, Akad. Nauk Ukrain. SSR Inst. Mat., Kiev (1977), 122-143 (Russian).

[23] _ Partially ordered sets of finite growth, Function. Anal. i Prilozhen., 19 (1982), no. 2, 72-73 (in Russian); English transl., Functional. Anal. Appl., 16 (1982), $135-137$.

[24] U. Revitskaya and A.G. Zavadskij, A matrix problem over a discrete valuation ring, Matematicheskij Sbornik 190; English transl., 6 (1999), 59-82.

[25] C. Rodriguez and A.G. Zavadskij, On corepresentations of equipped posets and their differentiation, Revista Colombiana de Matemáticas 39 (2006).

[26] C. Rodriguez, On corepresentations of one parametric equipped posets, São Paulo Journal of Mathematics Sciences 4 (2010), 141-175.

[27] W. Rump, Differentiation for orders and artinian rings, Algebras and Representation Theory 7 (2004), 395-417.

[28] D. Simson, Linear Representations of Partially Ordered Sets and Vector Space Categories, Gordon and Breach, London, London, 1992. 
[29] A. Shkabara and A.G. Zavadskij, Commutative quivers and matrix algebras of finite type (1976).

[30] A.V. Zabarilo and A.G. Zavadskij, One-parameter equipped posets and their representations, Functional. Anal.i Prilozhen 34 (2000), no. 2, 72-75 (Russian); English transl., Functional Anal. Appl. 34 (2.000), no. 2, 138-140.

[31] A.G. Zavadskij, Differentiation with respect to a pair of points, Matrix problems, Collect. sci. Works. Kiev (1977), 115-121 (in Russian).

[32] A.G. Zavadskij and V.V. Kirichenko, Semimaximal rings of finite type, Mat Sbornik 103 (1977), 323-345 (in Russian).

[33] _ Torsion-free modules over primary rings, Journal of Soviet Mathematics 11 (1979), no. 4, 598-612.

[34] A.G. Zavadskij, The Auslander-Reiten quiver for posets of finite growth, Topics in Algebra, Banach Center Publ. 26 (1990), Part 1, 569-587.

[35] - An algorithm for posets with an equivalence relation, Can. Math. Soc. Conf. Proc. 11 AMS (1991), 299-322.

[36] _ On tame vectorspace categories I, CMS Conf. Proc. 18 (1996), 685-720. Representation Theory of Algebras(Cocoyoc, 1994).

[37] _ On tame vectorspace categories II, CMS Conf. Proc. 24 (1998), 525-561. Representation Theory of Algebras(Geiranger, 1996).

[38] _ _ Tame equipped posets, Linear Algebra Appl. 365 (2003), 389-465.

[39] _ Equipped posets of finite growth, Representations of Algebras and Related Topics, AMS, Fields Inst. Comm. Ser. 45 (2005).

[40] - On two point differentiation and its generalization, Algebraic Structures and their Representations, AMS, Contemporary Math. Ser. 376 (2005).

[41] _ On the Kronecker problem and related problems of linear algebra, Linear Algebra Appl. 425 (2007), no. 1, 26-62.

[42] _ A matrix problem over a central quadratic skew field extension, Linear Algebra Appl. 428 (2008), 393-399.

[43] - Representations of generalized equipped posets and posets with automorphisms over Galois field extensions, Journal of Algebra 332 (2011), 386-413. 